\title{
DIE „BYZANTINISCHE FRAGE“ UND DIE POLNISCHE KULTUR: EIN BIBLIOGRAPHISCHER BERICHT
}

\begin{abstract}
Die bisherige Analyse der schriftlichen Quellen hat nachgewiesen, dass die Beziehungen zwischen Polen und Byzanz nur sporadisch waren. ${ }^{1}$ Die Archäologie und Kunstgeschichte ändern dieses Bild nicht. Obwohl Polen seit Anbeginn seiner Zeiten an russische Gebiete, welche sich im Kreis der byzantinischen Tradition befinden, angrenzt, ist es schwer über den unmittelbaren Einfluss der Kunst des Byzantinischen Reiches zu sprechen. ${ }^{2}$ Von den Zeiten des
\end{abstract}

${ }^{1}$ S. u.a.: O. Haleck1, La Pologne et l'Empire Byzantin. Byzantion 7 (1932) 4I-67; T. WAsILEWskI, Couronnement de l'an 1000 à Gniezno et son modèle byzantin, in: T. Manteuffel - A. Gieysztor (Hrsg.), L'Europe aux IX'-XI ${ }^{e}$ siècles. Aux origines des Etats nationaux. Varsovie 1968, 46I-472; M. SALAMON, „Amicus" or "hostis“? Boleslav the Valiant and Byzantium. Byzantinoslavica 54 (1993) II4-I2O; T. CONLEY, Byzantine Culture in Renaissance and Baroque Poland. Warsaw 1994, 23-28; G. Prinzing, Byzantinische Aspekte der mittelalterlichen Geschichte Polens. Byzantion 64 (1997) 459-484, hier bibliographische Nachweise; M. Salamon, Polen und Byzanz - Wege der Begegnung, in: G. Prinzing - M. Salamon (Hrsg.), Byzanz und Ostmitteleuropa 950-I453. Beiträge zu einer table-ronde des XIX International Congress of Byzantine Studies, Copenhagen 1996. Wiesbaden I999, I5I-I64. Weitere Literatur z.B. bei M. Wotoszyn, Zwei Episoden aus der Geschichte der polnischbyzantinischen Kontakte des 10. bis 12. Jahrhunderts, in: M. KaimaKamova - M. Salamon - M. SmorąG-RóżyCKa (Hrsg.), Byzantium, New Peoples, New Powers: The Byzantino-Slav Contact Zone, from the Ninth to the Fifteenth Century. Cracow 2007, I6I-182.

${ }^{2}$ A. RóżyCKa-Bryzek, Polska sztuka średniowieczna a Bizancjum i Ruś. Slavia Orientalis 38 (1989) Nr.3-4, 337-350; A. RóżyCKA-BryZEK, Polish Medieval Art in Relation to Byzantium and Rus', in: Le origini e lo sviluppo della cristianità slavo-bizantina. Roma 1992, 355-375. Neuerdings u.a.: M. SMORĄG-RÓżYCKA, Kościół wschodni i jego sztuka na ziemiach Rzeczypospolitej, in: Cerkiew - Wielka Tajemnica. Sztuka cerkiewna od XI wieku do 1917 roku ze zbiorów polskich. Katalog wystawy zorganizowanej przez Muzeum Zamek Górków w Szamotułach i Muzeum Początków Państwa Polskiego w Gnieźnie, kwiecieńsierpień 200I. Gniezno 200I, 17-24; M. WoŁosZYN, Europa Środkowo-Wschodnia a cywilizacja bizantyńsko-ruska w X-XIII w. Próba interpretacji źródeł archeologicznych. Prace Komisji Środkowoeuropejskiej I4 (2006) 7-48; die bisherigen Zusammenstellungen der polnischen byzantinologischen Bibliographie sind nicht komplett: J. S. ALLEN (Hrsg.), Literature on Byzantine Art I892-1967, Bd.I, Teil 2. Washington 1973, 151-152. W. CERAN, 
Herrschergeschlechtes der Piasten, die Herrscher Polens bis in das I4. Jh., bis heute gibt es nur wenige Werke der byzantinischen Kunst. Zum Import der Bilder, Kreuze und Goldarbeiten trugen vor allem die Familienbeziehungen zwischen polnischen und russischen Herzogen bei (Geschenke, Weihgaben). ${ }^{3}$ Inmitten dieser Objekte, welche in den Inventaren der königlichen ${ }^{4}$ und kirchlichen Schatzkammern, als opere Graeco, tabula Graeca oder Graecae dispositionum bezeichnet wurden, sind u.a. folgende erwähnenswert: die Lanckoroński Gemme (Byzanz, 6-7. Jh.), ${ }^{5}$ der sog. Adalbert-Kelch in der Schatzkammer der Kathedrale von Gniezno (Byzanz, Io. Jh.?; Polen 4. Viertel 13. Jh.), ${ }^{6}$

Historia i bibliografia rozumowana bizantynologii polskiej (I800-I998), Bd.I-2. Łódź 200I; Bibliography of Polish Byzantine and Post-Byzantine Studies. Series Byzantina 4 (2006) 83-155.

${ }^{3}$ A. RóżyCKa-Bryzek, Sztuka w Polsce piastowskiej a Bizancjum i Ruś, in: S. StęPIEŃ (Hrsg.), Polska-Ukraina. Iooo lat sąsiedztwa, Bd.2. Przemyśl I994, 295305; M. MYśLIŃSKI, Bericht über das Projekt: Byzantinische und spätbyzantinische Kunstwerke in den polnische Sammlungen, in: Prinzing - Salamon, Byzanz (wie Anm.I) 185-189. Ich übergehe hier einige byzantinischen Handschriften aus dem I4.I5. Jahrhundert der ehemals preussischen Bibliothek, die sich jetzt in der JagiellonenBibliothek befinden; vgl. S. SKRZYNIARZ, Die Darstellung des hl. Dionysios Areopagites in einem Byzantinischen Manuskript aus dem I4. Jahrhundert in der Sammlung der Jagiellonischen Bibliothek in Krakau, in: Prinzing - Salamon Byzanz (wie Anm.I) 207-2I3.

${ }^{4}$ M. MYŚLIŃSKI, Les oeuvres de l'art byzantin dans le Trésor du Royaume Polonais, in: G. Prinzing - M. Salamon (Hrsg.), Byzantium and East Central Europe, Cracow 2001, 193-195; M. MYŚLIŃSKI, Dzieła sztuki bizantyńskiej i ruskiej w Skarbcu Koronnym na Wawelu, in: M. KoKoszko - M. J. LeszKA (Hrsg.), Byzantina Europaea. Księga Jubileuszowa ofiarowana Profesorowi Waldemarowi Ceranowi. Łódź 2007, 425-430.

${ }^{5}$ M. MYśLIŃSKI, Wczesnobizantyńska gemma w zbiorach Zamku Królewskiego na Wawelu. Studia Waweliana II-I2 (2002-2003) 25I-253 (hier weitere Literatur). Über andere Gemmen aus den polnischen Sammlungen: M. MYśLIŃSKI, Sceny gonitw rydwanów na hipodromie w Konstantynopolu - dwie gemmy w zbiorach Muzeum Narodowego w Krakowie, in: Ars Graeca - Ars Latina. Studia dedykowane Profesor Annie RóżyckiejBryzek. Kraków 200I, 49-54; M. MYŚLIŃSKI, Gemmy późnoantyczne i bizantyńskie w polskich kolekcjach muzealnych. Biuletyn Historii Sztuki 68 (2006) 229-233.

${ }^{6}$ Der Kelch ist um die Mitte des 19. Jh. stark restauriert worden. Vgl. P. SkUBiszewski, Der sog. Kelch des hl. Adalbert - Ein Geschenk Ottos III. an die Kathedrale in Gniezno?, in: H. L. NickEL (Hrsg.), Byzantinischer Kunstexport. Seine gesellschaftliche und künstlerische Bedeutung für die Länder Mittel- und Osteuropas. Halle 1978, 199-217; P. SKUBISZEWSKI, Eine Gruppe romanischer Goldschmiedearbeiten in Polen (Trzemeszno, Czerwińsk). Jahrbuch der Berliner Museen 22 (I980) 35-90, besonders 42-43, 7I-74; P. SkUBISZEWSKI, Sog. Adalbert-Kelch aus Tremessen (Trzemeszno), in: M. BRANDT - A. EggeBreCht (Hrsg.), Bernward von Hildesheim und das Zeitalter der Ottonen. Katalog der Austellung 1993. Bd.2, Hildesheim - Mainz am Rhein 1993, 82-83; P. SKUBISZEwSKI, Kielich agatowy tzw. św. Wojciecha, in: P. MrOZOWSKI A. BADACH (Hrsg.), Ornamenta Ecclesiae Poloniae. Skarby sztuki sakralnej X-XVIII w. Warszawa 1999, 68-69. 
die Heliodor Gemme im staatlichen Museum von Przemyśl (umstrittene Datierung), ${ }^{7}$ die verschollene Staurothek aus der Kollegiatskirche von Tum bei Łęczyca (Konstantinopel, 2. Hälfte II. Jh.?), ${ }^{8}$ das Diptychon im Nationalmuseum in Warschau (Konstantinopel, Io.-II. Jh.), ${ }^{9}$ das Krönungskreuz der polnischen Könige (gehörte Kaiser Manuel I. Komnenos?), ${ }^{10}$ das spätbyzantinische hölzerne Kreuz des Georgios Laskaris im Museum der Fürsten Czartoryski in Krakau (1570), ${ }^{11}$ die Mosaikikone im Kloster des Klarissenordens in Krakau (Konstantinopel?, Ende I2. Jh.-Anfang I3. Jh.), ${ }^{12}$ die Staurothek-Ikone aus der Schatzkammer auf dem Wawel (Byzanz, 2. Hälfte I2. Jh.), ${ }^{13}$ Textilfragmente. ${ }^{14}$

J. SPIER, Medieval Byzantine Magical Amulets and their Tradition. Journal of the Warburg and Courtauld Institutes 56 (1993) 59, Nr.57, Abb. 5c.

${ }^{8}$ M. WALICKI, Kolegiata w Tumie pod Łęczycą. Łódź 1938, 52-58; T. H. OrŁowsKI, Bizantyński relikwiarz Krzyża Świętego z kolegiaty w Tumie pod Łęczycą. Biuletyn Historii Sztuki 5I (1989) 223-245.

${ }^{9}$ R. Ratkowska, An East Christian Diptych with the Heortological Cycle. Bulletin du Musée National de Varsovie 6 (1965) 92-II5; A. CuTler, Mistaken Novelity: Problems of Ivory Carving in the Christian East ( $12^{\text {th }}$ and $13^{\text {th }}$ Centuries). Biuletyn Historii Sztuki 70 (2008) 269-284. Zu den byzantinischen Elfenbeinplaketten aus der Sammlung des Czartoryski-Museums in Krakau: P. GroTowskI, Dwie bizantyńskie plakiety z kości słoniowej w zbiorach Muzeum Książąt Czartoryskich (problem autentyczności w świetle badań konserwatorskich i analizy stylowej). Series Byzantina 5 (2007) 39-54.

${ }^{10} \mathrm{E}$. DĄвROwsKa, La relique de la Vraie Croix appartenant à Manuel Comnène. Bulletin de la Société Nationale des Antiquaires de France 1987, 93-I13; E. DĄBROWSKA, Jeszcze o relikwii Krzyża Świętego i relikwiarzu koronacyjnym królów polskich. Kwartalnik Historyczny IOO (1993) 3-I3; E. DĄвROWSKA, Groby, relikwie i insygnia. Studia z dziejów mentalności średniowiecznej. Warszawa 2008.

${ }^{11}$ J. RożYCKI, Ein unbekanntes Werk des Georgios Laskaris: das geschnitzte Kreuz im Museum der Fürsten Czartoryski Krakau. Byzantina et Slavica Cracoviensia 2 (1994) 83-96.

${ }^{12}$ B. DąB-KalinowsKa, Die Krakauer Mosaikikone. JÖB 22 (1973) 285-299; A. Różycka-Bryzek, Matka Boska Hagiosoritissa, in: A. WŁodarek (Hrsg.), Pax et Bonum. Skarby klarysek krakowskich. Katalog wystawy. Arsenał Muzeum Czartoryskich, wrzesień-październik 1999. Kraków 1999, 42-46, hier weitere Literatur; A. RóżYCKA-BryzeK, Mozaikowa ikona Matki Boskiej Hagiosoritissy w klasztorze ss. klarysek w Krakowie, in: Magistro et amico - amici discipulique. Lechowi Kalinowskiemu w osiemdziesięciolecie urodzin. Kraków 2002, 405-426.

${ }^{13}$ M. MYŚLIŃSKI, Stauroteka bizantyńska ze Skarbca Koronnego na Wawelu. Studia Waweliana 5 (1996) 5-32.

${ }^{14}$ B. BiedrońsKa-SŁotowa, Early is ${ }^{\text {th }}$ Century Byzantine and Mamluk Textiles from Wawel Cathedral, Cracow. Bulletin du Centre International d'Études des Textiles Anciens 72 (1994) 13-19. 
Ein ganz eigenes Problem, welches ich hier nur andeuten kann, sind die archäologischen Fundstücke, ${ }^{15}$ z.B. Münzen, ${ }^{16}$ Schnallen, emaillierte Kreuze, Steinikonen, Schellen und Glöckchen. ${ }^{17}$ Die in Polen gefundenen Enkolpien stammen aus der Kiever Rus'. ${ }^{18}$

Ein interessantes Beispiel des künstlerischen Imports ist eine Gruppe der russisch-byzantinischen Wandmalereien aus dem I5. Jh., deren ikonographisches Programm an die Innenräume der gotischen Kirchen angepasst wurde. ${ }^{19}$ Das Patronat des Königs Władysław Jagiełło (ca. I362-I434) und seines Sohns Kazimierz (I427-I492) kann man - als Kulturphänomen - vergleichen mit dem Patronat der normannischen Herrscher Siziliens des I2. Jh., obwohl die polnischen Kunstwerke pro-

${ }^{15}$ E. GA̧SSOWSKA, Bizancjum a ziemie północno-zachodnio-słowiańskie we wczesnym średniowieczu. Studium archeologiczne. Wrocław - Warszawa - Kraków - Gdańsk 1979.

${ }^{16} \mathrm{M}$. MYśLIŃSKI, Les monnaies byzantines inconnues de l'epoque de la dynastie des Paléologues dans la collection du Musée National de Wrocław. Notae Numismaticae Zapiski Numizmatyczne 2 (1997) I58-164; A. GLIKSMAN, Obieg monet bizantyńskich na terenie Wielkopolski w X-XI wieku. Slavia Antiqua 44 (2003) 97-II9; M. WołoszYN, Monety bizantyńskie z VI-VII w. w Polsce na tle środkowoeuropejskim, in: P. KaCZANOwSKI - M. PARCZewSKI (Hrsg.), Archeologia o początkach Słowian. Kraków 2005, 637-680

${ }^{17} \mathrm{M}$. Wołoszyn, Die byzantinischen Fundstücke in Polen. Ausgewählte Probleme, in: Prinzing - Salamon, Byzantium (wie Anm.4) 49-59, hier weitere Literatur; M. WoŁoszyn, Zwischen Gnesen, Krakau und Kiev. Archäologie über frühmittelalterliche polnisch-altrussische Beziehungen und die Gestaltung des polnisch-altrussischen Grenzgebietes, in: M. Dęilec - M.Wotoszyn (Hrsg.), Frühzeit Ostmitteleuropas: Das polnisch-ukrainische Grenzgebiet aus archäologischer Perspektive. Rzeszów 2007, 177-204.

${ }^{18}$ M. P. Kruk - A. Sulikowska-GąSKa - M. WołoszYn, Sacralia Ruthenica Early Ruthenian and Related Metal and Stone Items in the National Museum in Cracow and National Museum in Warsaw/Dzieła staroruskie bądź z Rusią związane z metalu i kamienia w Muzeum Narodowym w Krakowie i w Muzeum Narodowym w Warszawie. Warszawa 2006.

${ }^{19}$ A. RóżyCKA-Bryzek, Byzantine Frescoes in Medieval Poland, in: Évolution générale et développements régionaux histoire de l'art. Actes du XXII ${ }^{\mathrm{c}}$ Congrès International d'Histoire de l'Art, Bd.r. Budapest 1969, 225-23I; A. RÓŻYCKA-BRYZEK, Byzantinisch-Slawische Malerei im Staate der Jagiellonen, in: Polen im Zeitalter der Jagiellonen 1386-1572, Schallaburg 8. Mai - 2. November 1986. Wien 1986, 172-178; A. RóżYCKA-BRYZEK, Bizantyńsko-ruskie malowidła w Polsce wczesnojagiellońskiej: problem przystosowań na gruncie kultury łacińskiej, in: STĘPIEń, Polska-Ukraina (wie Anm.3) 307-326; A. SULIKOWSKA-GĄSKA, Malarstwo cerkiewne w państwie polskolitewskim. Na skrzyżowaniu tradycji, in: A. Mironowicz - U. PAWLUCZUK - W. WaLCZAK (Hrsg.), The Orthodox Church in the Balkans and Poland. Connections and Common Traditions. Białystok 2007, 277-286; P. Ł. GROTOWSKI, On the Margins of Meaning: Some Remarks on Gesture as Depicted in the Orthodox Frescoes of Roman Catholic Churches in Poland. Biuletyn Historii Sztuki 70 (2008) 163-176. 
vinziell sind. ${ }^{20}$ Die künstlerische Andersartigkeit der Deckenmalereien wurde noch in der Renaissance während der Visitationen der katholischen Bischöfe geschätzt. ${ }^{21}$ Die Mehrheit der Fresken wurde dann aber im Zeitalter des Barock zerstört oder überstrichen. Die Entdeckungen in Sandomierz, Lublin, Wiślica und der Anfang der konservatorischen Arbeiten, sowie der wissenschaftlichen Forschungen fällt erst auf das Ende des 19. Jh.

Heute sind nicht mehr vorhanden die Deckenmalereien in der Kathedrale in Gniezno, in der Benediktinerkirche auf Łysa Góra und im Schlafzimmer Jagiełłos auf dem Wawel. ${ }^{22}$ Erhalten sind dagegen die Fragmente der Wandmalereien in der Kollegiatskirche der Geburt Mariae in Sandomierz (Ende des I4. Jh. - I434), ${ }^{23}$ in welchen die Forscher nach Einflüssen der balkanischen Kunst suchen, und in der Kollegiatskirche der Geburt Mariae in Wiślica (Ende des I4. Jh. - Anf. des I5. Jh.) - ein Werk von russischen Malern. ${ }^{24}$ Die Kreuzkapelle im Dom St. Wenzeslaus und Stanislaus in Krakau (3. Hälfte des I5. Jh.) wird der Schule von Pskow zugeschrieben, ${ }^{25}$ die Schlosskapelle der Hl. Dreifaltigkeit in Lublin (14I8) zeigt die

${ }^{20}$ A. RÓŻYCKA-BRYZEK, O uwarunkowaniach patronatu króla Władysława Jagiełly nad malarstwem bizantyńsko-ruskim w Polsce, in: S. STĘPIEŃ (Hrsg.), Polska Ukraina. I00o lat sąsiedztwa, Bd.5. Przemyśl 2000, I49-I56.

${ }^{21}$ A. RóżYCKA-Bryzek, Malarstwo cerkiewne w polskiej tradycji historycznej i w badaniach naukowych, in: Sztuka cerkiewna diecezji przemyskiej. Materiały z międzynarodowej konferencji naukowej 25-26 marca 1995. Łańcut 1999, 15-16.

${ }^{22}$ A. RóżYCKA-BRYZEK, Niezachowane malowidła "graeco opere” z czasów Władysława Jagiełly. Analecta Cracoviensia I9 (1987) 295-318.

${ }^{23}$ A. RóżYCKA-BryzeK, Malowidła "greckie” fundacji Jagiełły w kolegiacie sandomierskiej - dzieje i stan badań. Prace Komisji Wschodnioeuropejskiej 4 (1997) 5-17; A. Ró̇̇YCKA-BryZEK, Malowidła ścienne bizantyńsko-ruskie, in: A. S. LABUDA - K. SECOMSKA, Malarstwo gotyckie w Polsce, Bd.I. Warszawa 2004, I55-I84; A. RóżYCKABRYZEK, Obraz „Czuwającego Emmanuela” w malowidłach Kaplicy Świętokrzyskiej na Wawelu. Modus. Prace z historii sztuki 7 (2006) 33-52.

${ }^{24}$ A. Ró̇̇CKA-BRYZEK, Bizantyńsko-ruskie malowidła ścienne w kolegiacie wiślickiej. Folia Historiae Artium 2 (1965) 47-82; P. GrotowsKI, Dwie nieznane sceny w prezbiterium kolegiaty wiślickiej, in: Ars Graeca (wie Anm.5) I45-154; A. GronEK, $\mathrm{O}$ wątku ewangelicznym w bizantyńsko-ruskich malowidłach w wiślickiej kolegiacie, in: W. Bazus - W. Walanus - M. WalczaK (Hrsg.), Artifex Doctus. Studia ofiarowane profesorowi Jerzemu Gadomskiemu w siedemdziesiątą rocznicę urodzin, Bd.I. Kraków 2007, 179-191.

${ }^{25}$ A. RÓżYCKA-BrYZEK, Bizantyńsko-ruskie malowidła ścienne w kaplicy Świętokrzyskiej na Wawelu. Studia do Dziejów Wawelu 3 (1968) 175-293; P. GroTowskı, Kraków, in: LABUDA - SECOMSKA, Malarstwo (wie Anm.23) Bd.2, II5-117; A. RóżYCKABRYZEK, Cykl maryjny we freskach "graeco opere” fundacji Władysława Jagiełly w katedrze sandomierskiej. Modus. Prace z historii sztuki 7 (2006) 33-53. 
Zusammenhänge mit den künstlerischen Milieus von Nowgorod und Twer auf, sowie mit denen der westlichen Rus'. ${ }^{26}$ Im Jahr 2005 wurden weitere Reste der Fresken in der Marienkapelle im Krakauer Dom entdeckt.

Außerhalb des königlichen Mäzenats entstanden die Wandmalereien in der orthodoxen, gemauerten Wehrkirche von Posada Rybotycka (I5. Jh.) - Werk einer einheimischen Schule, ${ }^{27}$ und in Supraśl (I532-I557; I944 zerstört) - in der wissenschaftlichen Literatur verbunden mit balkanischen Künstlern (Serbien, Athos). ${ }^{28}$

Einen besonderen Platz nimmt die armenische Kunst ein, welche von den Siedlerkolonien in Lemberg, Kamieniec Podolski und Zamość geschaffen wurde. ${ }^{29}$ Die Kathedralen in Lemberg (1363) und Zamość (I6. Jh?) verbinden die traditionelle armenische Architektur mit der örtlichen künstlerischen Tradition. ${ }^{30}$ Weltbekannt ist das Lemberger Evangeliar von Skevra (II98/1999) reich verziert mit Figural- und Ornamentmotiven. ${ }^{31}$

Die ältesten Ikonen in Polen sind Importe. ${ }^{32}$ Das bis heute am meisten verehrte Bild Polens ist die Ikone der Mutter Gottes von

${ }^{26}$ A. RóżYCKA-BryzeK, Bizantyńsko-ruskie malowidła w kaplicy zamku lubelskiego. Warszawa 1983; A. RóŻYCKA-BRYZEK, Freski bizantyńsko-ruskie fundacji Jagiełly w kaplicy zamku lubelskiego. Lublin 2000. S. auch ein Sammelband: Kaplica Trójcy Świętej na Zamku Lubelskim. Historia, teologia, sztuka, konserwacja. Materiały sesji zorganizowanej w Muzeum Lubelskim 24- 26 kwietnia 1997 roku. Lublin 1999.

${ }^{27}$ A. RóżyCKA-Bryzek, Program ikonograficzny malowideł cerkwi w Posadzie Rybotyckiej, in: Symbolae historiae artium. Studia $\mathrm{z}$ historii sztuki Lechowi Kalinowskiemu dedykowane. Warszawa 1986, 349-365.

${ }^{28}$ A. SiemaszKo, Malowidła ścienne cerkwi Zwiastowania w Supraślu. Rekonstrukcja programu ikonograficznego. Zeszyty Naukowe Uniwersytetu Jagiellońskiego. Prace $z$ historii sztuki 2I (1995) 13-63; A. SIEMASZKO, Rekonstrukcja programu ikonograficznego cerkwi Zwiastowania monasteru supraskiego, in: Z dziejów monasteru supraskiego. Materiały międzynarodowej konferencji naukowej „Supraski monastyr Zwiastowania Przenajświętszej Bogarodzicy i jego historyczna rola w rozwoju społeczności lokalnej i dziejach państwa", Supraśl-Białystok, IO-II czerwca $2005 \mathrm{r}$. Białystok 2005, I65-I76; A. SIEMASZKO, Freski z Supraśla. Unikatowy zabytek XVIwiecznego pobizantyńskiego malarstwa ściennego. Białystok 2006.

${ }^{29}$ S. Ausstellungskatalog: Ormianie polscy - odrębność i asymilacja. Kraków 1999.

${ }^{30} \mathrm{~J}$. ChrZĄSzCZEwski, Kościoły Ormian polskich. Warszawa $200 \mathrm{I}$ (hier eine Bibliographie).

${ }^{31}$ G. PrinzING - A. Schmidt (Hrsg.), Das Lemberger Evangeliar. Eine wiederentdeckte armenische Bilderhandschrift des I2. Jahrhunderts. Wiesbaden 1997.

${ }^{32}$ M. P. KRUK, Ikony w świątyniach rzymsko-katolickich dawnej Rzeczypospolitej, in: M. BorowsKa - M. KalinowsKa - J. ŁawsKi - K. TomaszuK (Hrsg.), Filhellenizm w Polsce. Rekonesans. Warszawa 2007, II7-132. Vgl. E. ŚnieŻyńSKA-STOLot, The 
Częstochowa, welche vermutlich im I2. Jh. in Italien entstand, danach wurde sie im I4. Jh. übermalt (auch in Italien?) und im I5. Jh. in Polen. ${ }^{33}$ Dieses Bild, als eines der ersten nördlich der Alpen, erhielt die päpstlichen Kronen im Jahr $1717 .{ }^{34} \mathrm{Als}$ Wunderikone galt auch die Mutter Gottes von Chełm (Byzanz?, I2. Jh.?), welche mit den Königen Johann II. Kasimir und Michael Korybut Wiśniowiecki im 17. Jh. während den Kriegsexpeditionen wanderte und im Jahr 1765 gekrönt wurde. $^{35}$

Weitere Untersuchungen erfordert die Ikonenmalerei des polnisch-russischen Grenzgebietes, wo außer den Arbeitsräumen der Kloster weltliche Malereiwerkstätten in den Städten (u.a. Lemberg, Przemyśl) tätig waren. ${ }^{36}$ Die stilistische Vielfalt der aufbewahrten

Criterion of „Icon” in Polish History of Art, in: H. L. Nickel (Hrsg.), Ikone und frühes Tafelbild. Halle 1988, 171-173.

${ }^{33}$ A. RóżyCKa-BryzeK - J. GadomsKi, Obraz Matki Boskiej Częstochowskiej w świetle badań historii sztuki. Studia Claromontana 5 (1984) 27-50; E. ŚNIEŻYŃSKAStolot, Gnadenbild der Mutter Gottes im Kloster zu Częstochowa, in: Polen im Zeitalter der Jagiellonen (wie Anm.19) 192-193; A. RoŻYCKA-BrYZEK, L'immagine d'Odighitria du Częstochowa: origini, culto e la profazione Ussita. Arte Cristiana 75 (1988) 79-92; A. WITKOWSKA, Czenstochau, in: R. BÄUMER - L. SCHEFFCZYK (Hrsg.), Marienlexikon, Bd.2. St. Ottilien 1989, I2O-I2I; A. RóżyCKA-BryZeK, Obraz Marki Boskiej Częstochowskiej. Pochodzenie i dzieje średniowieczne. Folia Historiae Artium 26 (1990) 5-26; R. Maniura, Pilgrimage do Images in the Fifteenth Century. The Origins of the Cult of Our Lady of Częstochowa. Woodbridge 2004; J. PIROŻYŃSKI, Die alteste gedruckte deutschsprachige Überlieferung der Legende vom Marienbild in Tschenstochau. Gutenberg-Jahrbuch 7I (1996) 88-96. Zu den Kronen und dem Gewand der Tschenstochauer Mutter Gottes neuerdings: E. SMULıKOWSKA, Korony i sukienki obrazu Matki Boskiej Częstochowskiej jako przejaw kultu królowej korony polskiej. Studia Claromontana 23 (2005) 55-88; I. KaBALA, Dressing the Hodegetria in Czestochowa. Word \& Image 22 (2006) 275-284. Die anthropologische Methode benutzt A. NIEDźwIEDź, Obraz i postać. Znaczenia wizerunku Matki Boskiej Częstochowskiej. Kraków 2005. Den Forschungsstand berichtet W. KURPIK, Częstochowska Hodegetria. Łódź - Pelplin 2008, 73-87.

${ }^{34}$ A. J. BaranowsKI, Koronacje wizerunków maryjnych w czasach baroku. Zjawisko kulturowe i artystyczne. Warszawa 2003, 13-15. Die Besprechung des Problems auf Englisch: A. J. Baranowski, The Coronation of Miraculous Images of the Holy Madonna in Poland, Bohemia and Moravia. A Cultural Phenomenon. Biuletyn Historii Sztuki 64 (2002) 197-225. Zum Kult dieser Ikone: A. GIL, Źródła kultu ikony Matki Boskiej Chełmskiej. Z dziejów religijności w XVII-wiecznej Rzeczypospolitej. Series Byzantina 2 (2004) 203-218.

${ }^{35}$ Baranowski, Koronacje (wie Anm.35) 54-55.

${ }^{36}$ J. KłosińSKA, Ikonen aus Polen. Recklinghausen 1966; M. PrZeźDZIECKA, O małopolskim malarstwie ikonowym w XIX wieku. Studia nad epilogiem sztuki cerkiewnej w diecezji przemyskiej i na terenach sąsiednich. Wrocław - Warszawa - Kraków - Gdańsk 1973; R. BıSKUPSKI, Ikony w zbiorach polskich. Warszawa I99I; A. RóżYCKABryzeK, Orthodox Monasteries in South-Eastern Poland and their Art, in: Trends in Orthodox Monasticism $9^{\text {th }}-20^{\text {th }}$ Centuries. International Symposium, Thessaloniki, 
Ikonen, von welchen die ältesten auf das I5. Jh. datiert sind, leitet sich aus den Impulsen aus den näheren und entfernten Milieus her: von Rus' (Nowgorod, Moskau) über den Balkan (Serbien, Bulgarien) bis Slowenien und Bukowina. ${ }^{37}$ Die Evolution der Malerei bestand in der Auflockerung der byzantinischen Kanones unter dem Einfluss der gotischen Kunst sowie der Renaissance- und Barockkunst, ${ }^{38}$ besonders nach der Kirchenunion von Brest (1596). ${ }^{39}$ Parallel zum Prozess der

September $28^{\text {th }}$-October $2^{\text {nd }}$, Athens 1996, I25-I38; J. CZAJKOWSKI (Hrsg.), Ikona Karpacka. Sanok 1998; M. P. KRUK, Zachodnioruskie ikony Matki Boskiej z Dzieciątkiem w wieku XV i XVI. Kraków ²00o; A. GroneK, Ikony Męki Pańskiej. O przemianach w malarstwie cerkiewnym ukraińsko-polskiego pogranicza. Kraków 2007. Die beste Auswahl an Abbildungen im Bildband: M. JANOCHA, Ikony w Polsce. Od średniowiecza do współczesności. Warszawa 2008 (hier auch eine Bibliographie 439-442). Neuerdings: A. SiemaszKo, O diaku Michale Aleksandrowiczu Zbrożewiczu i mało znanych faktach dotyczących kontaktów wschodnich ziem Rzeczypospolitej z Bałkanami około połowy wieku XVI, in: Ars Graeca (wie Anm.5) 169-173; M. P. KRUK, Balkan Features in Ruthenian Icon Painting in Historical Poland, in: PrINZING - Salamon, Byzantium (wie Anm.4) 237-246; M. P. KruK, Balkan Connections of Ruthenian Icons of the Former Republic of Poland Exemplified by Iconography and Inscriptions, in: MironowicZ - PAWLUCZUK - WALCZAK (wie Anm.18) 287-297; A. SiEMASZKO - J. TOMALSKA, Ikona Znamienia Matki Boskiej z Topilca, in: W. WaLANUS - M. WaLCZAK - J. WolańSKa (Hrsg.), „Żeby wiedzieć”. Studia dedykowane Helenie Małkiewiczównie. Kraków 2008, 219-228.

${ }^{37}$ Eine historische Einleitung: S. Rohdewald - S. WiederkeHr - D. Frick, Transkulturelle Kommunikation im Großfürstentum Litauen und in den östlichen Gebieten der Polnischen Krone: Zur Einführung, in: S. Rohdewald - S. Frick S. Wiederkehr (Hrsg.), Litauen und Ruthenien. Studien zu einer transkulturellen Kommunikationsregion (I5.-18. Jahrhundert). Wiesbaden 2007, 7-33.

${ }^{38}$ R. GRZĄDZIELA, Proweniencja i dzieje malarstwa ikonowego po północnej stronie Karpat w XV i na pocz. XVI w., in: J. Czajkowski (Hrsg.), Łemkowie w historii i kulturze Karpat, Bd.2. Sanok 1994, 207-267; R. BISKUPSKI, Sztuka Kościoła prawosławnego i unickiego na terenie diecezji przemyskiej w XVII i pierwszej połowie XVIII wieku, in: STĘPIEŃ, Polska-Ukraina (wie Anm.3) 35I-37o; M. JANOCHA, Ukraińskie i białoruskie ikony świąteczne w dawnej Rzeczypospolitej. Problem kanonu. Warszawa 2002; J. GIEMZA, Wir tragen unsere Hymne vor - die Heilige Dreieinigkeit erweckt zum neuen Leben. Ikonen aus dem Karpatenland in Polen, vom I5. bis 18. Jahrhundert, in: Unter Deinen Schutz... Ikonen vom I5. bis 18. Jahrhundert aus den polnischen Karpaten. Nowy Sącz 2006, 22-40. M. P. KRUK, Sztuka własna i obca. $\mathrm{Na}$ marginesie badań nad zachodnioruskim malarstwem ikonowym, in: KOKOSZKO LESZKA (wie Anm.4) 327-344.

${ }^{39}$ K. Mart - P. Kondraciuk - W. Deluga, Sztuka i liturgia Kościoła greckokatolickiego w 400. rocznicę Unii Brzeskiej. Chełm - Zamość 1996; Sztuka iluminacji i grafiki cerkiewnej. Warszawa 1996; M. SMORĄG-RóżYCKA, Integracyjna rola sztuki w dobie unii brzeskiej. Krakowskie Zeszyty Ukrainoznawcze 5/6 (1996/1997) 147-155; M. JANOCHA, Unia Brzeska a malarstwo ikonowe XVII wieku. Dialog wyznań czy dialog kultur?, in: J. HaRASIMOWICZ (Hrsg.), Sztuka i dialog wyznań w XVI i XVII wieku. Materiały sesji Stowarzyszenia Historyków Sztuki. Wrocław, listopad 1999. Warszawa 2000, 399-415. 
Okzidentalisation verlief die Umgestaltung der Ikonenmalerei in der Volkskunst. ${ }^{40}$ Eine Ausnahme bilden Ikonen der Altgläubigen, wovon sich die größten Anhäufungen im nördlichen Ostpolen befinden. ${ }^{41}$ Die provinzielle Ikonenmalerei hat im 20. Jh. die Avantgarde (Jerzy Nowosielski ${ }^{42}$ ) und die naive Kunst (Nikifor ${ }^{43}$ ) beeinflusst. Nowosielski ist Gestalter der Ausstattungen vieler orthodoxer und katholischer Kirchen, ${ }^{44}$ er bleibt aber ein Schaffender, bezaubert von den Traditionen der byzantinischen Kunst, welcher gleichzeitig - als moderner Künstler - versucht, das Phänomen der Ikonenmalerei auf den Bereich der weltlichen Kunst zu übertragen. ${ }^{45}$

In den Ostgebieten Polens hat sich ein Architekturtyp herausgebildet, welcher den byzantinisch-russischen Plan (dreiteilig: Naos, Sanktuarium und Vorhalle mit I oder 3 Kuppeln; sehr selten auf dem Grundriss in Form des griechischen Kreuzes mit einer zentral gelegener Kuppel) mit den westeuropäischen Elementen verband. Anfangs waren dies Ziegel- und Steinbauten, später aus Holz in einer Form einer kleinen, einschiffigen Kirche. ${ }^{46}$ Die orthodoxe Architektur des 19. Jh. verliert die byzantinisch-russische Abstammung und wiederholt einerseits die russischen offiziellen staatlichen Muster, anderseits adaptiert sie den Neobyzantinismus von Teophil von Hansen. ${ }^{47}$ Ein

${ }^{40} \mathrm{~J}$. KŁosińSKA, Ikonen aus Polen. Warsaw 1989, II.

${ }^{41}$ D. SCHeffel, In Search of Poland's Old Believers. Anthropology Today 6 (1990) Nr.5, 2-8; M. SALWIŃSKI, Ikonen der Altgläubigen aus Polen, in: M. SAlWIŃSKI (Hrsg.), Della Polonia Icone a Verona. Verona 2006, 37-44; M. KRUSZONA, Ikonensammlung in Szamotuły, und K. MazuruK, Ikonenmuseum in Supraśl, in: E. Schneider M. SALwIŃSKI (Hrsg.), Ikone - menschliche Hypostase des Göttlichen. Ikonen der Altgläubigen aus polnischen und deutschen Museen und Privatsammlungen, 17. bis 20. Jahrhundert. Schweinfurt 2008, II-I2.

${ }^{42}$ M. PORĘBSKI, The Eschatological Realism of Jerzy Nowosielski. Artibus et Historiae Io (1989) I71-214; A. KosTOŁOWSKI - W. NowACZYK (Hrsg.), Nowosielski. Poznań I993; M. PoręBSKI, Nowosielski. Kraków 2003; P. CYPRIAŃSKI - A. SzCZEPANIAK (Hrsg.), Jerzy Nowosielski. Kraków 2003.

${ }^{43}$ A. BanACH, Nikifor. Warszawa 1984; Z. Wolanin (Hrsg.), Nikifor. Olszanica 2000; A. JACKOwSKI, Świat Nikifora. Gdańsk 2005.

${ }^{44}$ Der Katalog der sakralen Realisationen: K. CZERni, Nowosielski. Kraków 2006, 209-215.

${ }^{45}$ M. P. KRUK, Sztuka Jerzego Nowosielskiego i tradycja malarstwa prawosławnego w dawnej Rzeczypospolitej, in: K. KorotKICH - J. ŁAWSKI (Hrsg.), Apokalipsa. Symbolika - tradycja - egzegeza, Bd.r. Białystok 2006, 467-47I.

${ }^{46}$ Zur orthodoxen Architektur: R. BRYKOWSKI, Drewniana architektura cerkiewna na koronnych ziemiach Rzeczypospolitej. Warszawa 1995.

${ }^{47}$ Vgl. P. KRASNY, Architektura cerkiewna na ziemiach ruskich Rzeczypospolitej, 1596-1914. Kraków 2003; P. CYNAlewSKA-KuCZMA, Architektura cerkiewna Królestwa Polskiego narzędziem integracji z Imperium Rosyjskim. Poznań 2004. 
sehr interessantes Beispiel der Realisation der neobyzantinischen Architektur ist die Goldene Kapelle bei der Kathedrale in Posen Piastenmausoleum (I. Hälfte des I9. Jh.). ${ }^{48}$

Es war eigentlich ein Zufall, dass die erste Monographie über ein Kunstwerk in der polnischen Kunstbeschreibung - Explication historique d'un tableau en relief ( 1752 ) von Bischof Adam Stanisław Grabowski eine Abhandlung über eine byzantinische Elfenbeinskulptur ist. ${ }^{49}$

Das Wissen über Byzanz hatte im 19. Jh. in Polen drei Hauptquellen: (I) die wissenschaftliche Literatur der Aufklärung, vor allem Johann Joachim Winckelmann - eine polnische Adaptation Geschichte der Kunst des Altertums von Stanislaus Kostka Potocki erschien erst I8I5; $;^{50}$ (2) Belletristik - sehr populär war in Polen z.B. der Roman Bélisaire von Jean-François Marmontel, ${ }^{51}$ und (3) die Reiseberichte, in denen man sehr oft die Orientalisierung Byzanz' bemerken kann. ${ }^{52}$ Byzanz spielte auch eine wichtige Rolle im nationalen Diskurs. ${ }^{53}$ Auf Grund einer nicht eindeutigen mittelalterlichen Notiz entstand im 19. Jh. die Ansicht, dass Polen das Christentum in östlichem Ritus angenommen hätte (heutzutage hat sich diese Hypothese als falsch erwiesen)..$^{54}$

${ }^{48}$ T. S. JAROSZEWSKI, Uwagi o stylu bizantyjskim w architekturze polskiej XIX wieku, in: D. KonstantYNOW - P. PASZKIEWICZ (Hrsg.), Kultura i polityka. Wpływ polityki rusyfikacyjnej na kulturę zachodnich rubieży imperium rosyjskiego (I7721915). Warszawa 1994, 77-78. Z. OstrowsKa-KęBŁowsKA, Dzieje Kaplicy Królów Polskich czyli Złotej w katedrze poznańskiej. Poznań 1997.

${ }^{49} \mathrm{~K}$. KORDEK, Explication historique d'un tableau en relief biskupa Grabowskiego, in: Myśl o sztuce. Materiały Sesji zorganizowanej z okazji czterdziestolecia istnienia Stowarzyszenia Historyków Sztuki, Warszawa, listopad 1974. Warszawa 1976, I35-I42.

${ }^{50}$ M. SMORĄG-Ró̇YCKA, Problematyka badań nad sztuką bizantyńską: główne kierunki i perspektywy badawcze, in: M. SMORĄG-RóżCKA (Hrsg.), Sztuka średniowiecznego Wschodu i Zachodu. Osiągnięcia i perspektywy poznawcze u progu XXI wieku. Kraków 2002, 59-62.

${ }^{51}$ E. RzadKowska, Francuskie wzorce polskich Oświeconych. Studium o recepcji J. F. Marmontela w XVIII w. Warszawa 1989, 92-100, I57-160.

52 U.a. E. RaczYnSKI, Malerische Reise in einigen Provinzen des Osmanischen Reiches. Breslau I824. Vgl. auch J. MAJ, Kazimierz Chłędowski a kultura bizantyńska, in: J. MızıołeK - J. MAJ (Hrsg.), Kazimierz Chłędowski: pisarz i badacz kultury. Krosno 2007, 159-18I.

${ }_{53}$ M. DĄBROWSKA, La vision moscoutaire de Byzance et le byzantinisme allemand de Koneczny ou Byzance sans Byzance. Organon 28/29 (1999/2000) 257-268; M. DĄBROWSKA, Byzance, source des stereotypes dans la conscience des Polonais, in: M. F. Auzepy (Hrsg.), Byzance en Europe. Paris 2003, 43-54.

${ }^{54}$ Salamon, Polen (wie Anm.I) 153-154. Neuerdings: M. Janion, Niesamowita Słowiańszczyzna. Fantazmaty literatury. Kraków 2007, 98-I21. 
In der zweiten Hälfte des $19 \mathrm{Jh}$. begann im polnischen wissenschaftlichen Milieu die Erforschungen der orthodoxen Kunst. ${ }^{55}$ Wichtig war auch die Entstehung der Struktur des Denkmalpflegedienstes - seit I889 wirken die Kommissionen für die Erhaltung der historischen Denkmale in West- und Ostgalizien. ${ }^{56} \mathrm{I} 88 \mathrm{I}$ entstand in Lemberg die Archäologische Landesgesellschaft, welche seit I882 die Zeitschrift "Przegląd Archeologiczny” [Archäologische Rundschau] veröffentlicht, und 1885 den ersten Kongress der Archäologen organisierte. ${ }^{57}$ Diesen Kongress begleitete die erste Polnisch-Russische archäologische Ausstellung, welche eine wissenschaftliche Diskussion zum Thema einer selbständigen Ikonenmalerei in den süd-östlichen Gebieten Polens auslöste. ${ }^{58}$

Die systematischen Untersuchungen für byzantinische und postbyzantinische Kunst ${ }^{59}$ initiierte in Polen Vojeslav Molè (I886-1973) Absolvent der Universität Wien, ein Schüler von Josef Strzygowski und Max Dvořak, der erste Inhaber des Lehrstuhls für Kunstgeschichte der Slawischen Völkern an der Jagiellonen-Universität in Krakau. ${ }^{60}$ Eine Schülerin von Molè - Anna Różycka-Bryzek (1928-2005) - schuf im

55 W. Deluga, Studies in Orthodox Church Painting in Central Europe. Arte Cristiana 9I (2003) 355-366, 437-446; W. DELUGA, Polish-Ukrainian Research of the Post-Byzantine Art in $19^{\text {th }}$ and $20^{\text {th }}$ Century, in: M. RaKocija (Hrsg.), Niš and Byzantium. Third Symposium, Niš, 3-5 June 2004. The Collection of Scientific Works. Niš 2005, 489-502.

${ }^{56}$ A. MAŁkIEWICZ, Z dziejów polskiej historii sztuki. Studia i szkice. Kraków 2003, 22, hier frühere Literatur.

${ }^{57} \mathrm{Vgl}$. Bericht von Dzieduszycki in Mittheilungen der K.K. Central-Commission zur Erforschung und Erhaltung der Kunst und historischen Denkmale I2 (I886) CLXXIII-CLXXVIII.

${ }^{58}$ L. WIERZBICKI - M. SoKOŁOWSKI, Wystawa archeologiczna polsko-ruska urządzona we Lwowie w roku 1885, Lwów I885. J. KŁosińsKA, Ikony. Kraków 1973, I6-19. Vgl. KRUK, Sztuka (wie Anm.39) 328-329.

${ }^{59}$ A. RożYCKA-BRYZEK, Zarys historyczny badań nad bizantyńsko-ruskimi malowidłami ściennymi w Polsce. Biuletyn Historii Sztuki 27 (1965) 29I-294; W. CERAN, Główne osiagnięcia polskich badań nad historią sztuki bizantyńskiej (do roku 1998), in: SMORAG-RÓżYCKA (wie Anm.5I) 9-43. S. auch: W. DelugA, Rozwój badań naukowych nad sztuką cerkiewną na przełomie XIX i XX wieku, in: J. GIEMZA (Hrsg.), Zachodnioukraińska sztuka cerkiewna. Dzieła - twórcy - ośrodki - techniki. Materiały z międzynarodowej konferencji naukowej, IO-II maja 2003 roku. Łańcut 2003, 74-82.

${ }^{60}$ L. Kalinowski, Wojsław Molè (1886-1973). Folia Historiae Artium II (1975) 5-19; A. RożycKa-BryzeK, Wojsław Molè. Zeszyty Naukowe UJ. Prace z Historii Sztuki I9 (1990) 85-96; A. MaŁkiewicz, Wojsław (Vojeslav) Molè, in: J. Purchla (Hrsg.), Kraków i Lublana a mit Europy Środkowej. Materiały międzynarodowej konferencji zorganizowanej przez Międzynarodowe Centrum Kultury w Krakowie w dniach II-I2 grudnia 2006. Kraków 2007, I53-160. 
Jahr 1989 an derselben Hochschule den ersten Lehrstuhl für Byzantinische Kunstgeschichte in Polen. ${ }^{61}$

Einerseits sind somit die Forschungen über den Einfluss der byzantinischen Kultur auf die polnische Kunst weit fortgeschritten, andererseits sind jedoch die Erkenntnisse über den Einfluss auf die Literatur nur sehr fragmentarisch und deshalb ist hier eine Synthese schwer. ${ }^{62}$

Ein Streitgegenstand sind die Einflüsse der byzantinischen hymnischen Literatur in der Bogurodzica - dem ältesten religiösen Lied Polens (entstand vermutlich zwischen dem I2. und 13. Jh.). ${ }^{63}$

Im Jahr I509 übersetzte Nikolaus Kopernikus (1573-I543) auf Lateinisch die Briefe von Theophylaktos Simokattes. ${ }^{64}$ Bemerkenswert sind zahlreiche Übersetzungen der Schriften der Kirchenväter im 16. Jh. (u.a. Basileios der Grosse, Kyrillos von Alexandreia, Kyrillos von Jerusalem, Gregor von Nazianz, Gregor von Nyssa, Johannes Chrysostomos, Johannes von Damaskos). Die patristischen Übersetzungen finden sich auch in Postilla catholica (I573) und Postilla mniejsza (1596) von Jakub Wujek (I54I-I597) - zwei Sammlungen katholischer Predigten. ${ }^{65}$ Eine der Hymnen von Gregor von Nyssa übersetzte Andrzej Trzecieski (vor 1530-ca. 1584/85) - ein Protestant und Dichter. ${ }^{66}$ Byzantinische Texte haben herausgegeben u.a.: der

${ }^{61}$ J. MAJ, Professor Anna Różycka-Bryzek (1928-2005). Bulletin of British Byzantine Studies 33 (2007) 108-I09; M. SMORĄG-RóżYCKA, Professor Anna Różycka-Bryzek (I928-2005), in: Kaimakamova - Salamon - SMOrąG-Różycka (wie Anm.I) II-22; M. SmorĄG-RożyCKA, Anna Różycka-Bryzek (1928-2005). Folia Historiae Artium II (2007) I39-I45.

${ }^{62}$ Die enzyklopädische Zusammensetzung: J. Z. LıCHAŃsKI, Bizancjum w literaturze polskiej, in: O. JUREWICZ (Hrsg.), Encyklopedia kultury bizantyńskiej. Warszawa 2002, 78-8I. Die Bibliographie der Rezeption der altchristlichen Literatur in Polen vom I5. bis i8. Jh.: J. CZERniATOWICZ - C. MaZUR, Recepcja antyku chrześcijańskiego w Polsce, Bd.I. Lublin 1978.

${ }^{63}$ R. Mazurkiewicz, Deesis. Idea wstawiennictwa Bogarodzicy i św. Jana Chrzciciela w kulturze średniowiecznej. Kraków 1994, 170-238.

${ }^{64}$ P. CZARTORYSKI, Tradycja literacka łacińskich przekładów epistolografów greckich a Kopernikowski przekład "Listów obyczajowych, sielskich i miłosnych" Teofilakta Symokatty wydany w Krakowie w 1509 r. Odrodzenie i Reformacja 33 (1988) I37-146. Kritische Reedition der Ausgabe von I509: TeOfILAKT Symmokata, Listy. Warszawa 1953.

${ }^{65}$ Ausführliche Bibliographie: T. WITCZaK, Wujek Jakub, in: Dawni pisarze polscy od początków piśmiennictwa do Młodej Polski. Przewodnik biograficzny i bibliograficzny, Bd.5. Warszawa 2004, 118-122.

${ }^{66}$ G. KROKошsкI, Gregorii Nazianzeni carmen ab Andrea Tricesio (I565) latinis versibus paraphrastice redditum. Eos 34 (1932/1933) 347-348. 
Kardinal und Humanist Stanislaus Hosius (1504-I579), ${ }^{67}$ der Historiker Marcin Kromer (I5I2-I589) und der Philologe Stanislaus Grzepski (I524-I570). ${ }^{68}$ Die orthodoxen Geistlichen übersetzten und veröffentlichten auch Texte in der altkirchenslawischen Sprache und auf Russisch. ${ }^{69}$ Man muss hier zumindest erwähnen, dass sich in den polnischen Bibliotheken-außerden kyrillischenAltdrucken-übertausend kyrillische Handschriften befinden, welche in der Mehrheit aus den lokalen orthodoxen oder unierten Monasterien und Kirchen stammen, nur wenige sind Importe aus dem Moldau-Gebiet, der Rus' und dem Balkann. ${ }^{70}$ Die wertvollste darunter sind die Fragmente des berühmten Codex Suprasliensis, welcher im I. Viertel des II. Jh. entstand und eine der wichtigsten Quellen für die Untersuchungen über die slawischen Sprachen und deren Alphabet bleibt. ${ }^{71}$

Im I7. Jh. führt Krzysztof Kraiński (I556-I6r8) in Postylla (Bd.I-5, I6II-I6I8) viele Zitate byzantinischer Autoren an, u.a. von Nikephor Patriarch von Konstantinopel..$^{72}$ Der Jesuit und Philologe-Lexikograph Grzegorz Knapiusz (I564-I639) berücksichtigte im Thesaurus PolonoLatino-Graecus ${ }^{73}$ auch byzantinische Schriftsteller. Der Jurist Sebastian Jan Piskorski (I636-I707) publizierte Żywoty Ojców [Vatersleben]

${ }^{67}$ L. Longosz, Pisma św. Cyryla Jerozolimskiego. Vox Patrum 6 (1985) 269-270.

${ }^{68} \mathrm{H}$. BARYCZ, Stanisław Grzepski, in: Polski słownik biograficzny, Bd.9. Wrocław Kraków - Warszawa 1960-1961, 99-102.

${ }^{69} \mathrm{Zu}$ den Altdrucken: J. RuSEK - W. WITKOWSKI - A. NAUMOw (Hrsg.), Najstarsze druki cerkiewnosłowiańskie i ich stosunek do tradycji rękopiśmiennej. Materiały z sesji, Kraków 7-10 199I. Kraków 1993; Z. JAROSZEWICZ-PIERESŁ.AwCEW, Starowiercy w Polsce i ich księi. Olsztyn I995; Z. Jaroszewicz-PieresławCEW, Druki cyrylickie z oficyn Wielkiego Księstwa Litewskiego w XVI-XVIII wieku. Olsztyn 2003; Z. ŻURAWIŃSKA - Z. JAROSZEWICZ-PIERESŁAWCEW, Katalog druków cyrylickich XV-XVIII wieku w zbiorach Biblioteki Narodowej. Warszawa 2004.

${ }^{70}$ A. Naumow - A. Kaszlej (Hrsg.), Rękopisy cerkiewnosłowiańskie w Polsce. Katalog. Kraków 2004. Zur religiösen Polemikliteratur des 16. bis 18. Jh.: J. STRADOMSKI, Spory o „wiarę grecką” w dawnej Rzeczypospolitej. Kraków 2003.

${ }^{71}$ Die anderen Teile sind in der Universitätsbibliothek in Ljubljana (Cod. Kop. 2) und in der Russisch Staatlichen Bibliothek in Sankt Petersburg (Q. n. I. 72) aufbewahrt. Eine Bibliographie bei Naumow - KaSzlej (wie Anm.7I) 306.

72 J. TAzBIR, „Kopalnia najciekawszych szczegółów...” („Postylla” Krzysztofa Kraińskiego). Odrodzenie i Reformacja 28 (1983) 195-229.

${ }^{73}$ Thesaurus Polono-Latino-Graecus. Kraków 1621. Die folgenden Ausgaben: Kraków 1643, 1688. Die verkürzte polnisch-lateinische Version hatte bis Ende des 17 . Jh. ein Vielzahl an Ausgaben. Vgl. J. PuzYnina, „Thesaurus” Grzegorza Knapiusza. Siedemnastowieczny warsztat pracy nad językiem polskim. Wrocław Warszawa - Kraków 1961. Zu Kenntnissen der altgriechischen Literatur in Polen: J. CZerniatowicz, Recepcja poezji greckiej w Polsce w XVI-XVII wieku. Wrockaw Warszawa - Kraków 1966. 
(I688) - eine Anthologie mit Texten u.a. von Johannes Moschos und Theodoretos von Kyrrhos. 1688 erschien in Reimparaphrase die Legende von den Heiligen Barlaam und Josaphat - erstellt von Mateusz Ignacy Kuligowski (gest. nach 1699) in Anlehnung an die frühere lateinische Übersetzung. ${ }^{74}$ Das Schultheater der Jesuiten, welches auf dem Grund der imitativen Literaturtheorie entstand, verwandte die Anleihen an die klassische Literatur als Werkzeug. Aus der byzantinischen Geschichte besonders populär war Belizar. ${ }^{75}$

Die byzantinischen Themata erschienen auch in der polnischen Literatur des 19. Jh., welche oft Byzanz mit der ostslawischen Tradition und der russischen Okkupation identifizierte. Adam Mickiewicz (1798-1855), der größte polnische Dichter der Romantik, und auch Cyprian Kamil Norwid (I82I-1883) waren der Auffassung, daß Byzanz das stereotype orientalistische Schema nicht überschreite. ${ }^{76}$

Die wissenschaftlichen Studien über byzantinische Literatur begann in Polen mit Leon Sternbach (I864-I940), welcher mit einem Team die kritische Ausgabe der Werke von Gregor von Nazianz vorbereitete, aber dieses Projekt wurde leider nicht beendet. ${ }^{77}$

Byzanz betrifft direkt eine Tragödie von Tadeusz Miciński (I873I918) W mrokach ztotego patacu, czyli Bazilissa Teofanu [In den Dunkelheiten des Goldenen Palastes, oder Basilissa Theophanu] (entstand 1904, Druck 1908), deren Handlung zur Regierungszeit von Romanos II. Lakapenos, Nikephoros II. Phokas und Johannes I. Tzimiskes spielt. ${ }^{78}$ Das byzantinische Reich wird in diesem Werk als

${ }^{74}$ Królewic indyjski w polski strój przybrany albo Historia o św. Jozofacie królewicu indyjskim i o świętym Barlaamie pustelniku pustyniej Sennaar nazwanej. Kraków 1688.

75 Tragodiae Mauritius Belisarius. E codice manu scripto Uppsaliensi R 380 edidit, praefatione, apparatu critico, annotationibus insttruxit Z. Piszczek, Wratsilaviae 1971.

${ }^{76} \mathrm{~J}$. ŁawsKI, Bizancjum Mickiewicza. Cesarstwo Wschodnie w „Pierwszych wiekach historii polskiej", in: M. Kalinowska - B. Paprocka-Podlasiak (Hrsg.), Antyk romantyków - model europejski i wariant polski. Rekonesans. Toruń 2003, 205-244; M. KUZıAK, Bizancjum Mickiewicza (na podstawie „Literatury słowiańskiej”), in: J. ŁAWSKI - K. KOROTKICH (Hrsg.), Bizancjum - prawosławie - romantyzm. Tradycja wschodnia w kulturze XIX wieku. Białystok 2004, 339-351. Hier auch ein Studium: J. ŁAWSKI, O Norwidowskim rozumieniu bizantynizmu, 527-566.

${ }_{77}$ M. PLEZIA, Niedoszłe wydanie krakowskie pism św. Grzegorza z Nazjanzu, in: M. Plezia, Z dziejów filologii klasycznej w Polsce, Warszawa 1993, 272-305; K. T. WitczaK, Sternbach Leon Samuel, in: J. Starnawski (Hrsg.), Słownik badaczy literatury polskiej, Bd.5. Łódź 2002, 28I-283 (hier eine Bibliographie).

${ }^{78}$ S. u.a. P. MARCINIAK, W Bizancjum czyli nigdzie, „W mrokach złotego Pałacu czyli Bazilissa Teofanu" Tadeusza Micińskiego, in: BOROWSKA - KalINOWSKA - LAwSKI TomaszuK, Filhellenizm (wie Anm.33) 587-593; S. BrzozowsKA, Antynomie 
die zu verkommen drohende Welt gezeigt, welcher der Verfasser den jungen russischen Staat gegenüberstellt. Der Vorzug dieser Tragödie sind die Beschreibungen der Kirchen- und Palastinnenräume von Konstantinopel und der Zeremonien.

Eine Versuch, byzantinische Thematik in die Musik einzuführen, ist die Oper Król Roger [König Roger] (entstand 1918-I924; Premiere 1926) von Karol Szymanowski (I882-1937). ${ }^{79}$ Der Verfasser des Librettos war der hervorragende polnische Schriftsteller Jarosław Iwaszkiewicz (1894-1980). Der Hintergrund der Handlung, Sizilien in den Zeiten von Roger II., wurde um Elemente der orientalistischen und hellenistischen Kultur (Mythos von Apollon und Dionysos) bereichert. ${ }^{80}$

Die Geschichte von Byzanz seit dem 13. Jh. und des Lateinisches Kaiserreiches kann man in den Romanen von Zofia Kossak (I890-1968) finden - vor allem in der Tetralogie Krzyżowcy [Kreuzfahrer] (Bd.I4, 1935), in welchen das Bild des Kreuzzuges fern von der heroischen Legende ist. ${ }^{81}$ Eine der Kindererzählungen der Schriftstellerin - Puszkarz Orbano [Kanonier Orbano] (1936) - stellt eine Episode aus der Belagerung der Türken von Konstantinopel dar. ${ }^{82}$

Der Held eines Romanes von Tadeusz Parnicki (1908-1988) Srebrne orty [Silberne Adler] (1944) - ein junger irischer Mönch, der durch die mittelalterliche Welt um die Wende des II. und I2. Jh. reist, kam auch nach Byzanz. Eine Trilogie Twarz księzyca [Mondgesicht] (Bd.I2, 196I; Bd.3, 1967) von Parnicki bildet kulturelle Beziehungen zwischen Asien und Byzanz mit dem lateinischen Europa in Zeiten des

dionizyjskości w „Bazilissie Teofanu” Tadeusza Micińskiego. Pamiętnik Literacki 98 (2007) 7I-9I; P. MARCINIAK, Bizantyńskie misterium młodopolskiego poety: „W mrokach Złotego Pałacu czyli Bazilissa Teofanu” Tadeusza Micińskiego, in: J. ŁAWSKI - K. Korotkich (Hrsg.), Ateny, Rzym, Bizancjum. Mity śródziemnomorza w kulturze XIX i XX wieku. Białystok 2008, 685-689.

${ }^{79}$ K. Michałowski, Karol Szymanowski, I882-1937. Katalog tematyczny dzieł i bibliografia. Kraków 1967, 172-182 (hier die ältere Literatur).

${ }^{80}$ P. E. Carapezza, Król Roger między Dionizosem a Apollinem. Res Facta 9 (1982) 5O-6I; K. BERGER, King Roger's „Liebesleben”, in: M. BRISTIGER - R. SCRUTON P. Weber-Bockholdt (Hrsg.), Karol Szymanowski in seiner Zeit. München 1984, IOI-II2; E. BonIECKI, W orszaku Dionizosa. Mit dionizyjski Szymanowskiego i Iwaszkiewicza. Pamiętnik Literacki 80 (1989) I39-159; S. C. DownESS, Szymanowski, Eroticism and the Voices the Mythology. Aldershot 2003, 54-74.

${ }^{81}$ Ausführliche Bibliographie: A. SZAzAGan, Kossak Zofia, in: J. CZACHOwsKa - A. SzaŁagan (Hrsg.), Współcześni polscy pisarze i badacze literatury. Słownik biobibliograficzny, Bd.4. Warszawa 1996, 274-279.

${ }^{82}$ U. URBANIK, Po obu stronach murów. Ostatnie dni Konstantynopola jako inspiracja literacka. Kraków 2004, 75-77. 
Niedergangs des Imperium Romanum und der Durchdringung des Christentums mit der Antike. ${ }^{83}$ Marginal erscheint Byzanz in anderen Werken von Parnicki über einen Verteidiger Roms vor den barbarischen Angreifern: Aecjusz, ostatni Rzymianin [Aetius, der letzte Römer] (1937), Stowo i ciato [Wort und Körper] (1959), Śmierć Aecjusza [Tod von Aetius] (1966). ${ }^{84}$

Ausführlich über die Kriege von Belizar erzählt Hanna Malewska (19II-I983) im Roman Przemija postać swiata [Die Gestalt dieser Welt vergeht] (Bd.I-2, 1954), in dem das moralische Dilemma der Helden aus den dramatischen historischen Ereignissen entsteht. ${ }^{85}$

In der polnischen Gegenwartsdichtung sind byzantinische oder orthodoxe Fäden sehr selten zu finden, u.a. im Schaffen von Jerzy Harasymowicz-Broniuszyc (1933-1999), ${ }^{86}$ von dem Griechen Nikos Chadzinikolau und - als eine Ausnahme - von Wisława Szymborska, Nobelpreisträgerin 1996. Im Gedicht Mozaika bizantyjska [Byzantinisches Mosaik] führen zwei Figuren aus dem Mosaik einen parodistischen Dialog über Körperlichkeit und Geistigkeit. ${ }^{87}$

\section{Summary}

The article outlines briefly the problem of the influence of Byzantium on Polish culture.

The existing analyses of the written sources have revealed that the links between Poland and Byzantium were but sporadic. Archeology and art history do not seem to change this picture. Although ever since the beginning of its history, Poland was a next-door neighbor of Ruthenian provinces which belonged to the sphere of the Byzantine tradition, it is difficult to speak here of any direct influence of the art of the Byzantine Empire. Only a small number of Byzantine art works have survived in the Polish art collections until the present. No doubt, it

${ }^{83}$ Ausführliche Bibliographie: J. ZaWADZKA, Parnicki Teodor, in: CZACHOWSKA Szał.AGan (wie Anm.82) Bd.6. Warszawa 1999, 260-264. Vgl. A. JuszCZYK, Retoryka a poznanie. Powieściopisarstwo Teodora Parnickiego. Kraków 2004.

${ }^{84}$ S. SzYmuTKo, Parnicki: między historią a literaturą. Od „Aecjusza ostatniego Rzymianina” do „Słowa i ciała”. Pamiętnik Literacki 88 (1997) 79-94.

${ }^{85} \mathrm{Vgl}$. M. NowaK, Koncepcja dziejów w powieściach historycznych. Teodor Jeske-Choiński, Zofia Kossak, Hanna Malewska. Lublin 2009.

${ }^{86}$ Ausführliche Bibliographie: J. PtTera, Harasymowicz Jerzy, in: CzACHOwsKA Szał.AGan (wie Anm.82) Bd.3. Warszawa 1994, 201-205.

${ }^{87}$ S. BaLbus, Między stylami. Kraków 1993, 330-332; D. LưtVoGT, Untersuchungen zur Poetik der Wisława Szymborska. Wiesbaden 1998, 266-267. 
was the family ties between the Polish and the Ruthenian dukes which contributed to the import of paintings, crucifixes and jewelry (gifts, votive offerings). Archeological objects, such as e.g. coins and stone icons are relatively numerous. The engolpions which have been found in Poland can be traced back to the Kiev Ruthenia. An interesting example of an art import is a group of Ruthenian-Byzantine frescos dating back to the XIV century, whose iconographic program had been adjusted to the Gothic Catholic churches. As a cultural phenomenon, the patronage of King Ladislas Jagiello and of his son Casimir, can be compared that of the Norman rulers of Sicily in the XII century, although the Polish paintings are quite provincial.

A separate place should be reserved for the Armenian art created by the settlers in Lvov, Kamieniec Podolski and Zamosc which had been influenced by the local tradition. The icon painting and the architecture associated with the Orthodox Church whose stylistic variety constitute the outcome of a confrontation with Western art, require further study. Another research postulate concerns the analysis of the influence of Byzantium on Polish literature (editing, translation, reception) as well as music. 